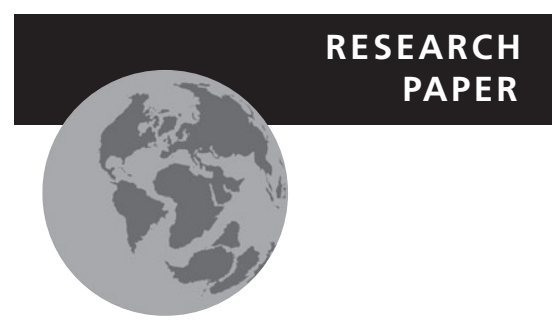

\title{
Are species-area relationships from entire archipelagos congruent with those of their constituent islands?
}

\author{
Ana M. C. Santos ${ }^{1,2 *}$, Robert J. Whittaker ${ }^{3}$, Kostas A. Triantis ${ }^{2,3}$, \\ Paulo A. V. Borges ${ }^{2}$, Owen R. Jones ${ }^{1}$, Donald L. J. Quicke ${ }^{1,4,5}$ and \\ Joaquín Hortal ${ }^{4}$
}

\begin{abstract}
${ }^{1}$ Department of Biology, Imperial College London, Silwood Park Campus, Ascot, Berkshire SL5 7PY, UK, ${ }^{2}$ Universidade dos Açores, Dep. de Ciências Agrárias - CITA-A (Azorean Biodiversity Group), Terra-Chã, 9700-851 Angra do Heroísmo, Portugal, ${ }^{3}$ Biodiversity Research Group, Oxford University Centre for the Environment, South Parks Road, Oxford OX1 3QY, UK, ${ }^{4}$ NERC Centre for Population Biology, Imperial College London, Silwood Park Campus, Ascot, Berkshire SL5 7PY, UK, ${ }^{5}$ Department of Entomology, Natural History Museum, Cromwell Road, London SW7 5BD, UK
\end{abstract}

${ }^{*}$ Correspondence: Ana M. C. Santos, Department of Biology, Imperial College London, Silwood Park Campus, Ascot, Berkshire SL5 7PY, UK.

E-mail: ana.margarida.c.santos@googlemail.com

\section{ABSTRACT}

Aim To establish the extent to which archipelagos follow the same species-area relationship as their constituent islands and to explore the factors that may explain departures from the relationship.

Location Thirty-eight archipelagos distributed worldwide.

Methods We used ninety-seven published datasets to create island species-area relationships (ISARs) using the Arrhenius logarithmic form of the power model. Observed and predicted species richness of an archipelago and of each of its islands were used to calculate two indices that determined whether the archipelago followed the ISAR. Archipelagic residuals (ArcRes) were calculated as the residual of the prediction provided by the ISAR using the total area of the archipelago, standardized by the total richness observed in the archipelago. We also tested whether any characteristic of the archipelago (geological origin and isolation) and/or taxon accounts for whether an archipelago fits into the ISAR or not. Finally, we explored the relationship between ArcRes and two metrics of nestedness.

Results The archipelago was close to the ISAR of its constituent islands in most of the cases analysed. Exceptions arose for archipelagos where (i) the slopes of the ISAR are low, (ii) observed species richness is higher than expected by the ISAR and/or (iii) distance to the mainland is small. The archipelago's geological origin was also important; a higher percentage of oceanic archipelagos fit into their ISAR than continental ones. ArcRes indicated that the ISAR underpredicts archipelagic richness in the least isolated archipelagos. Different types of taxon showed no differences in ArcRes. Nestedness and ArcRes appear to be related, although the form of the relationship varies between metrics.

Main conclusions Archipelagos, as a rule, follow the same ISAR as their constituent islands. Therefore, they can be used as distinct units themselves in largescale biogeographical and macroecological studies. Departure from the ISAR can be used as a crude indicator of richness-ordered nestedness, responsive to factors such as isolation, environmental heterogeneity, number and age of islands.

\section{Keywords}

Archipelagic residuals, archipelagos, geological origin, island biogeography, island species-area relationship, isolation, macroecology, nestedness, power model, $z$-values. 


\section{INTRODUCTION}

The species-area relationship is one of the most studied patterns in ecology, often being referred to as one of ecology's few laws (Schoener, 1976; Rosenzweig, 1995, 2003; Lawton, 1996, 1999). According to this 'rule', the number of species increases with area, and the rate of increase of species richness usually declines as area increases. There are a number of classifications for the different types of species-area relationships, depending on the scale at which they are analysed or whether they are measured from nested areas or not (e.g. Rosenzweig, 2003; Scheiner, 2003; Gray et al., 2004; Whittaker \& Fernández-Palacios, 2007; Dengler, 2009). Rosenzweig (1995) described three main scales (and types) of species-area relationships (four, if the point scale, which depends on sampling effort, is included), that correspond to different spatial/temporal scales. Following Whittaker \& Fernández-Palacios (2007) we may describe them as: (1) archipelagic (or island species-area relationship), which is the species-area relationship within a group of islands; (2) intraprovincial (or regional species accumulation curve), which is a species accumulation curve within a large continental area on a regional scale; and (3) inter-provincial, which encompasses different biotic regions (see also Rosenzweig, 2004; Triantis et al., 2008a). In the present work we focus on the archipelagic- or island-scale species-area relationship, henceforth termed the ISAR.

The form and slope of ISARs depend on the particular process(es) that dominate(s) the study system (immigration, speciation and extinction) (Rosenzweig, 1995; see also MacArthur \& Wilson, 1963, 1967; Triantis et al., 2008a; Whittaker et al., 2008; Borges \& Hortal, 2009). Some archipelagos (e.g. Hawaii, Galápagos, Azores) are sufficiently isolated, in space or time, to host a distinctive ('disharmonic') species pool, often drawn from more than one source region but with many shared elements (e.g. species or lineages) among the islands of the archipelago. The small number of colonization events, a characteristic of isolated archipelagos, creates homogeneity in the species colonizing these islands, which could imply that the processes establishing island species richness would largely be a property of the archipelago rather than of each constituent island on its own. Consequently each archipelago - or at least each remote archipelago - may be regarded as a unique entity similar to a province (Triantis et al., 2008a), regardless of the particularities of each island (see discussion in Whittaker et al., 2008). The homogeneity in the processes that build up island biotas would only be broken in cases where local (i.e. withinisland) idiosyncratic processes are predominant or the archipelago is composed by different subsets of islands that draw their components from significantly different species pools.

Regional factors acting on the whole of the archipelago (such as archipelago isolation, age, origin of the islands) are generally thought to have a consistent effect on the local patterns of diversity at the island level. Therefore, archipelagos are usually considered to be homogeneous entities, and it is thus not surprising that many authors have used complete archipelagos as single data points in their analyses (e.g. Wilson, 1961; Scott, 1972;
Schoener, 1976; Wright, 1983; Adler, 1992, 1994; Adler \& Dudley, 1994; Adler et al., 1995; Biber, 2002; Carvajal \& Adler, 2005; Hamilton et al., 2009). In fact, in his discussion of the so-called 'single large or several small' debate on the implications of island theory for reserve design, Rosenzweig (1995, p. 382) argued that 'the diversity and the area of whole archipelagos falls in the same species-area curve as the separate islands that constitute them', although stating that this hypothesis deserves further examination. However, formal tests of the assumption that archipelagos act as homogeneous entities in biogeographical terms are lacking. Should this assumption be rejected, either local ecological factors or the particular characteristics of the group studied (e.g. life-history traits, physiological adaptations) would predominate over classical island biogeography processes, challenging the universality of regional processes as the main factor shaping the diversity of island biotas.

Here, we evaluate whether entire archipelagos follow the same species-area relationship as that defined by their constituent islands. That is, we assess to what extent the total richness of the archipelago departs from the extrapolation of the ISAR to the total area of the islands that compose it. By implication we therefore test the assumption that archipelagos act as single entities in biogeographical terms, and hence the reliability of using them as single units in large-scale biogeographical and macroecological studies. We then evaluate our findings with regard to the type of taxon (invertebrates, vertebrates and plants), the geological origin (continental or oceanic) and isolation (distance to the mainland) of each archipelago, and the possible biological interpretation of departures of the archipelago data point from the ISAR, including its relationship with the nestedness of island biotas.

\section{METHODS}

Information on the species richness on islands was compiled from several sources for 97 archipelago/taxon combinations, pertaining to 38 island groups distributed worldwide (Appendix 1). Our data include archipelagos of oceanic (i.e. both true oceanic islands and continental fragments sensu Whittaker \& Fernández-Palacios, 2007, following Wallace, 1902), mixed, and continental origin and of varying size and degree of isolation from the closest mainland, and comprise data on several groups of vertebrates, invertebrates and plants. We excluded introduced species and subspecific taxa from all datasets. Total species richness for each archipelago was obtained by pooling the species lists of their constituent islands. We use the term 'ISAR' to refer to the species-area relationship constructed from the islands that constitute the archipelago (following Whittaker \& Fernández-Palacios, 2007). We also use 'archipelagic point' to refer to the total area and richness of the corresponding island group (archipelago).

For each archipelago/taxon combination, an ISAR regression model, with observed species richness $\left(S_{\text {obs }}\right)$ as the response variable and island area $(A)$ as the predictor, was constructed on a log-log scale. This follows the same approach as Arrhenius' (1921) power model $\log S_{\mathrm{obs}}=c+b \times \log A$, where $c$ is the 
intercept and $b$ the slope. In the particular case of the Canary Islands, ISARs were constructed for both (1) all seven main islands, and (2) all islands with the exception of Fuerteventura and Lanzarote, because these two islands are known to deviate from the general ISAR of their archipelago, being environmentally different from the younger islands located to the west and lacking mesic upland habitats (see discussion in Whittaker \& Fernández-Palacios, 2007, and Whittaker et al., 2008).

We were unable to find published protocols for evaluating the congruence of archipelagos and their ISARs. Logically, the archipelagic point in terms of species richness must fall somewhere between the species richness of the maximum individual island richness and the sum of the species richness of all islands in the archipelago, and archipelagic area is simply the sum of the area of all constituent islands. Therefore, the archipelagic point cannot be considered independent of the ISAR, and so we cannot formally test congruence using standard regression techniques. We therefore generated two simple indices to evaluate the departure of the archipelagic point from the richness predicted by extrapolating the ISAR to the total area for the whole archipelago (see below). These indices are based on an examination of the variation around the predicted ISAR but without any statistical probability being attached to them. However, having calculated the indices of fit, we do make use of inferential statistical tests to evaluate the strength of the relationships between these metrics and the properties of the archipelago and the type of taxon studied.

For each archipelago/taxon combination, we estimated archipelagic $\left(S A_{\text {pred }}\right)$ and constituent islands' $\left(S I_{\text {pred }}\right)$ species richness from the ISAR regression model. Values of $S I_{\text {pred }}$ were simply the fitted values of the regression model, while $S A_{\text {pred }}$ was estimated from the model using the total land-surface area of the archipelago as the predictor. We then calculated the residuals of the regression model (i.e. observed species richness minus $S I_{\text {pred }}$ ) and identified their maximum absolute value (MaxRes). We expressed MaxRes as a proportion (PropMaxRes) of $S I_{\text {pred }}$ for that particular observation [i.e. if the residual was 1 and the predicted log (species richness) for a given island's area was 3, then PropMaxRes would be 0.33]. We used PropMaxRes as an aid to examine the amount of disparity between the observed whole-archipelago species richness $\left(S A_{\mathrm{obs}}\right)$ and its predicted species richness $\left(S A_{\text {pred }}\right)$. If $S A_{\text {obs }}$ was within the bounds of $S A_{\text {pred }} \pm\left(S A_{\text {pred }} \times\right.$ PropMaxRes $)$, then we assume that we are not able to reject the hypothesis that the archipelago follows the ISAR. Conversely, if $S A_{\mathrm{obs}}$ was outside these bounds, we assume that this hypothesis can be rejected and the archipelago species richness is deemed to violate the ISAR. We conducted analogous analyses using the median of the residuals (MedRes) as a more conservative criterion, determining whether the archipelago falls into the interval defined by $S A_{\text {pred }} \pm\left(S A_{\text {pred }} \times\right.$ PropMedRes $)$ or not. Where the archipelago had an even number of islands the PropMedRes was calculated using the median values of the absolute residuals and of all the $S I_{\text {pred }}$.

The above procedure can be illustrated using the vascular plants of Cape Verde as an example (Table 1). For this dataset, the ISAR equation (on a $\log -\log$ scale) is $\log S=1.385+0.291 \times$ $\log A ; S A_{\text {pred }}$ and $S I_{\text {pred }}$ were obtained by applying this equation to the logarithm of the total land area of the archipelago $\left(4076 \mathrm{~km}^{2}\right)$ and to the logarithm of each island area, respectively (Table 1). The maximum residual was 0.157 (Santo Antão island) and PropMaxRes was 0.074 , which was obtained by calculating the proportion of MaxRes over its corresponding $S I_{\text {pred }}$ (2.127). The value obtained for $S A_{\text {pred }} \times$ PropMaxRes was $2.436 \times$ $0.074=0.179$, so the interval defined by $S A_{\text {pred }} \pm\left(S A_{\text {pred }} \times\right.$ PropMaxRes) was $2.436 \pm 0.179$. Since the logarithm of the total richness of the archipelago (2.441) lies inside this interval, we cannot reject that the archipelago is following the ISAR. The same procedure was followed using the median residual (0.087) instead of MaxRes.

We used the ratio between MaxRes and MedRes as a measure of the dispersion of the most distant island points within the archipelago for a preliminary evaluation of whether such dis-
Table 1 Values used to calculate the interval that delimits whether an archipelagic point is congruent with its island species-area relationship (ISAR) or not (for more details see text).

\begin{tabular}{lrrrrrrl}
\hline Islands & \multicolumn{1}{c}{$S_{\text {obs }}$} & \multicolumn{1}{c}{$A$} & $\log S_{\text {obs }}$ & $\log A$ & $S I_{\text {pred }}$ & $S A_{\text {pred }}$ & Abs Resid \\
\hline Boa Vista & 126 & 634.1 & 2.100 & 2.802 & 2.201 & 0.101 \\
Brava & 100 & 66.6 & 2.000 & 1.823 & 1.916 & 0.084 \\
Fogo & 154 & 474.8 & 2.188 & 2.677 & 2.164 & 0.023 \\
Maio & 117 & 279.0 & 2.068 & 2.446 & 2.097 & 0.029 \\
Sal & 92 & 221.5 & 1.964 & 2.345 & 2.068 & 0.104 \\
Santa Lucia & 61 & 36.7 & 1.785 & 1.565 & 1.841 & 0.055 \\
Santiago & 183 & 991.0 & 2.262 & 2.996 & 2.228 & 0.034 \\
Santo Antão & 192 & 787.3 & 2.283 & 2.896 & 2.127 & 0.157 \\
São Nicolau & 144 & 352.2 & 2.158 & 2.547 & 2.257 & & 0.099 \\
São Vincente & 146 & 232.8 & 2.164 & 2.367 & 2.074 & & 0.090 \\
Cape Verde & 276 & 4076.0 & 2.441 & 3.610 & - & 2.436 & - \\
\hline
\end{tabular}

$\mathrm{S}_{\mathrm{obs}}$ is the observed species richness of the vascular plants of Cape Verde, $A$ is the island/archipelago area expressed in $\mathrm{km}^{2}, \log S_{\mathrm{obs}}$ is the $\log$ arithm of $S_{\mathrm{obs}}, \log A$ is the $\operatorname{logarithm}$ of $A, S I_{\mathrm{pred}}$ is the predicted value for the species richness of each island, $S A_{\text {pred }}$ is the predicted value for the species richness of the archipelago, and Abs Resid is the absolute value of the residuals obtained by subtracting $S I_{\text {pred }}$ from $\log S_{\text {obs. }}$. 
persion would affect the results of our analyses. The cases in agreement with the ISAR showed similar MaxRes/MedRes ratios to those falling outside this relationship, for both the maximum and median residual criteria (not shown). The degree of dispersion of the distant island points was, however, higher for the cases meeting only the MaxRes criterion than for the cases meeting both criteria, as expected. We therefore assume that the degree of dispersion of the island points does not affect the probability of rejecting the congruence of an archipelagic point with its ISAR. Rather, it only affects the probability of meeting just the less restrictive or both criteria. Therefore, we expect differences in the criterion met to be mainly driven by the degree of dispersion of the islands, and not by factors causing the archipelagic point to depart from the ISAR. It follows that both criteria are equally reliable in terms of identifying whether an archipelago follows the ISAR of its constituent islands or not.

To determine if any archipelago and/or taxon characteristics account for the fit of an archipelago to its ISAR, we classified the datasets according to: (1) the kind of taxon they belong to (invertebrates, vertebrates or plants), and (2) the origin of the archipelago (continental, mixed or oceanic). In addition, we measured (3) the isolation of the archipelago as the smallest distance between any of the islands and the nearest mainland.

To obtain a measure of how much the archipelago departs from the ISAR, and allow an exploration of potential causes of deviation, we calculated the archipelagic residual (ArcRes) as the residual of the prediction provided by ISAR using the total area of the archipelago. To enable comparisons between different archipelagos, we standardized this residual by dividing it by the total richness observed in the archipelago. Using the above example of the vascular plants from Cape Verde, ArcRes would be calculated as $\left(\log S A_{\text {obs }}-S A_{\text {pred }}\right) / \log S A_{\text {obs }}$, that is $(2.441-$ 2.436)/2.441 $=0.002$. We used ArcRes as a response variable in regression models designed to explore the potential causes of deviation from the ISAR in the datasets that yielded significant regressions $(P<0.05)$. Potential explanatory variables included taxon type, geological origin of the archipelago and isolation, as above.

Finally, we explored whether there is a relationship between the magnitude of ArcRes and the degree of nestedness of the island biotas within the archipelago. Detailed data on species composition per island were not available for many of the datasets used for the former analyses. Due to this, and to avoid problems related to uneven sampling effort, we only analysed a reduced number of arthropod groups in two archipelagos we are more familiar with: the Azores and the Canary Islands (Table 2). These datasets, however, present an ample variation in ArcRes values (compared with the variation found in all studied datasets) and include cases that both enter and fail to enter in the median and maximum residual criteria (see Appendix 1). Given current debate on the most appropriate measure of nestedness (e.g. Almeida-Neto et al., 2007; Ulrich et al., 2009), we calculated two different measures: the nestedness metric based on overlap and decreasing fill (NODF; Almeida-Neto et al., 2008), as recommended by Ulrich et al. (2009); and the original Temperature (T) measure proposed by Atmar \& Patterson (1993). We com-
Table 2 Results of the nestedness analyses for several arthropod groups in the Azores and Canary Islands (data from Borges et al., 2005, and Izquierdo et al., 2004, respectively).

\begin{tabular}{llllll}
\hline Archipelago & $n$ & Taxon & ArchRes & T & NODF \\
\hline \multirow{2}{*}{ Azores } & 9 & All arthropods & $-0.701 \times 10^{-2}$ & 19.38 & 31.53 \\
& 9 & Arachnids & $-6.585 \times 10^{-2}$ & 20.87 & 31.04 \\
& 9 & Coleoptera & $-3.653 \times 10^{-2}$ & 18.29 & 23.35 \\
& 9 & Lepidoptera $^{*}$ & $2.376 \times 10^{-2}$ & 28.20 & 34.55 \\
Canary Islands & 7 & Arachnids $^{*}$ & $6.791 \times 10^{-2}$ & 33.62 & 14.49 \\
& 5 & Arachnids $^{\dagger}$ & $1.522 \times 10^{-2}$ & 34.72 & 16.92 \\
& 7 & Coleoptera $^{*}$ & $8.468 \times 10^{-2}$ & 40.83 & 23.05 \\
& 5 & Coleoptera $^{\dagger}$ & $2.405 \times 10^{-2}$ & 40.12 & 26.20 \\
& 7 & Lepidoptera $^{*}$ & $-6.093 \times 10^{-2}$ & 20.64 & 26.45 \\
& 5 & Lepidoptera $^{\dagger}$ & $-7.394 \times 10^{-2}$ & 15.57 & 30.98 \\
\hline
\end{tabular}

${ }^{*}$ Refers to all Canary Islands (see text).

$\dagger$ Refers to all Canary Islands except Fuerteventura and Lanzarote (see text).

$n$, number of islands.

ArchRes is the archipelagic residual (the residual of the prediction provided by the island species-area relationship (ISAR) using the total area of the archipelago, divided by the total richness observed in the archipelago), $\mathrm{T}$ is the original Temperature measure of nestedness (Atmar \& Patterson, 1993), and NODF is the nestedness metric based on overlap and decreasing fill proposed by Almeida-Neto et al. (2008).

Analyses were not performed for all arthropods in the Canary Islands due to the limit of 3000 lines (i.e. species) of the program used to compute the nestedness measure (ANINHADO; Guimarães \& Guimarães, 2006).

pared these measures and ArcRes by simple correlations and visual examination. Nestedness measures were calculated using ANINHAdo (Guimarães \& Guimarães, 2006). All other statistical analyses were performed using STAтistica 6.1 (StatSoft, 2003).

\section{RESULTS}

Seventy-two (74\%) out of the 97 ISARs examined had slopes significantly different from zero (Appendix 1). Most of the nonsignificant ISARs came from the Canary Islands (18 out of 25), but most of these became statistically significant after excluding the two more xeric and older islands, Fuerteventura and Lanzarote (see example in Fig. 1a,b). All subsequent results are based on the significant ISARs only. In these archipelago/taxon combinations, slopes (i.e. $z$-values) ranged from 0.08 to 0.94 , with the lower and upper quartiles being 0.22 and 0.52 , respectively; the median was 0.33 ; and the overall mean was 0.38 .

We could not reject the hypothesis that the archipelago species richness follows the ISAR in 63 cases (88\%) when using the maximum residual criterion (Appendix 1; Fig. 1b,f,g,h). The nine cases where the archipelago did not follow the ISAR according to this criterion had significantly lower slopes ( median $=0.21$, lower and upper quartiles $=0.18$ and 0.28 ) than those that did fit (median $=0.40$, lower and upper quartiles $=$ 0.27 and 0.53) (Mann-Whitney $U=156.5, Z=2.162, n_{1}=9$, $\left.n_{2}=63, P<0.05\right)$. Using the more conservative median residual 
criterion, only 45 out of 72 cases were congruent with their ISAR (63\%) (Appendix 1; see examples in Fig. 1b,g,h). Again, most of the cases in which the hypothesis of the archipelago following the ISAR was rejected showed lower slopes (median $=0.27$, lower and upper quartiles $=0.19$ and 0.33 ) than those where such a hypothesis was not rejected (median $=0.40$, lower and upper quartiles $=0.29$ and 0.58$)($ Mann-Whitney $U=301.5, Z=$ 3.559, $\left.n_{1}=27, n_{2}=45, P<0.001\right)$.

When the maximum residual interval was used, vertebrates had more archipelagos following their ISAR than invertebrates or plants (vertebrates $92 \%$, invertebrates $88 \%$, plants $78 \%$; Appendix 1). However, these differences were not significant $\left(\chi^{2}=1.06, P=0.59\right)$. Furthermore, when considering the interval defined by the median residual, the proportion of cases that were congruent with the ISAR was almost the same for each one of the three groups (vertebrates and invertebrates 62\%, and plants $\left.67 \% ; \chi^{2}=0.08, P=0.96\right)$. In any case, differences seemed to be stronger between archipelagos than between taxa. Some evidence of this came from the archipelagos for which we have data on different taxonomic groups; whereas in several taxa of the Canary Islands the archipelagic point fell outside its ISAR, this was not the case for the Azores or Cape Verde (Appendix 1).

Oceanic archipelagos were congruent with their ISAR more often than continental ones, according to the MaxRes criterion (95\%, vs. $76 \% ; \chi^{2}=5.43, P<0.05$ ). This difference was more pronounced when the MedRes criterion was used; while most oceanic archipelagos remain within their ISAR (75\%), only $41 \%$ of the continental archipelagos showed the same result $\left(\chi^{2}=7.98, P<0.05\right)$. Mixed archipelagos were not considered in these comparisons because of the small number of cases $(n=3)$. The distance from the archipelago to the mainland also had a significant effect on the probability of rejecting the hypothesis, since more isolated archipelagos were more congruent with their ISARs than less isolated ones (Mann-Whitney $U=159$, $Z=-2.12, n_{1}=9, n_{2}=63, P<0.05$ for the MaxRes; MannWhitney $U=413, Z=-2.26, n_{1}=27, n_{2}=45, P<0.05$ for the MedRes).

In Fig. 2 we show the ArcRes of the datasets with significant ISARs against their respective distances to the mainland, indicating also the type of taxon and geological origin of the archipelago. For continental islands ArcRes values showed a marginally non-significant negative relationship with isolation (Spearman $R=-0.33, P=0.08$ ), whereas for oceanic islands this relationship was significant and positive (Spearman $R=0.39$, $P<0.05)$. ArcRes of continental archipelagos and vertebrates showed higher variation than in other categories $(\mathrm{SD}=0.14$ and 0.16 , respectively, versus 0.12 for plants, 0.09 for invertebrates, 0.08 for mixed archipelagos and 0.07 for oceanic archipelagos). In fact, there were significant differences between the ArcRes values as a function of the geological origin of the archipelagos (i.e. ArcRes values were bigger for continental archipelagos; Mann-Whitney $U=344, Z=2.87, P<0.01$; mixed archipelagos were not considered for this analysis) but not between different taxa [Kruskal-Wallis $H$ ( 2 d.f., $n=72)=0.093 ; P=0.95$ ]. It is noteworthy that invertebrates from continental islands had more positive ArcRes values than negative ones, indicating that, in such cases, the ISAR tends to under-predict archipelagic species richness, especially in the least isolated islands. However, in the case of the invertebrates from oceanic islands the opposite relationship appears to occur: the least isolated archipelagos typically had negative ArcRes values while the most distant ones exhibited positive residuals. For all the other archipelago/taxon combinations the few data points available were much more scattered and therefore showed no evident trend.

The degree of nestedness of island biotas showed a clear relationship with ArcRes: the more nested a dataset, the lower (and negative) the archipelagic residual (Table 2, Fig. 3). In the cases analysed this pattern is more evident using the Temperature index (Spearman $R=0.83, n=10, t[n-2]=4.21, P<0.01$ ) than for NODF (Spearman $R=-0.48, n=10, t[n-2]=-1.54$, $P=0.16)$.

\section{DISCUSSION}

It is often commented that community ecology has few general rules or laws (Lawton, 1996, 1999, 2000; but see Gaston \& Blackburn, 2000; Simberloff, 2004; Ricklefs, 2008). One of the few exceptions is held to be the species-area relationship, which is widely applicable for all scales and types of organisms, from bacteria to vertebrates (Rosenzweig, 1995). The species-area relationship has commonly been described for discrete geographic units, such as islands within an archipelago (Rosenzweig, 1995; Whittaker \& Fernández-Palacios, 2007). However, it is not unusual to lump together data on the constituent islands of archipelagos by adding island areas and combining island species lists to obtain the overall area and richness of the archipelagos (e.g. Wilson, 1961; Scott, 1972; Wright, 1983; Adler et al., 1995; Carvajal \& Adler, 2005; among others). Although this allows the use of these data in large-scale analyses, it also implies that the archipelagos as a whole follow the same relationship with area that their constituent islands do, an assumption that has never been evaluated before.

We have shown that archipelagos do often follow the same ISAR as their constituent islands. In the majority of the cases studied, the archipelagic point is congruent with its ISAR, which begs the question of why whole archipelagos should follow the same species-area relationship as their constituent islands? The answer must be related to the endogenous dynamics of the system (speciation, immigration and extinction), which are determined by a number of regional factors such as total area of the archipelago, number of islands, environmental heterogeneity, isolation and geological age. These factors act as local filters for the regional processes acting over the species pool of the archipelago (see Ricklefs, 2007, 2008). Given the importance of regional processes common to all their constituent islands, many archipelagos can be considered to behave as a coherent entity for the different processes establishing species diversity. Interestingly, as a consequence of source pool effects there is a close association between species-area and local-regional richness relationships (see Srivastava, 1999; He et al., 2005), so species richness on individual islands is to some extent a reflection of the species pool of the archipelago. 
A. M. C. Santos et al.
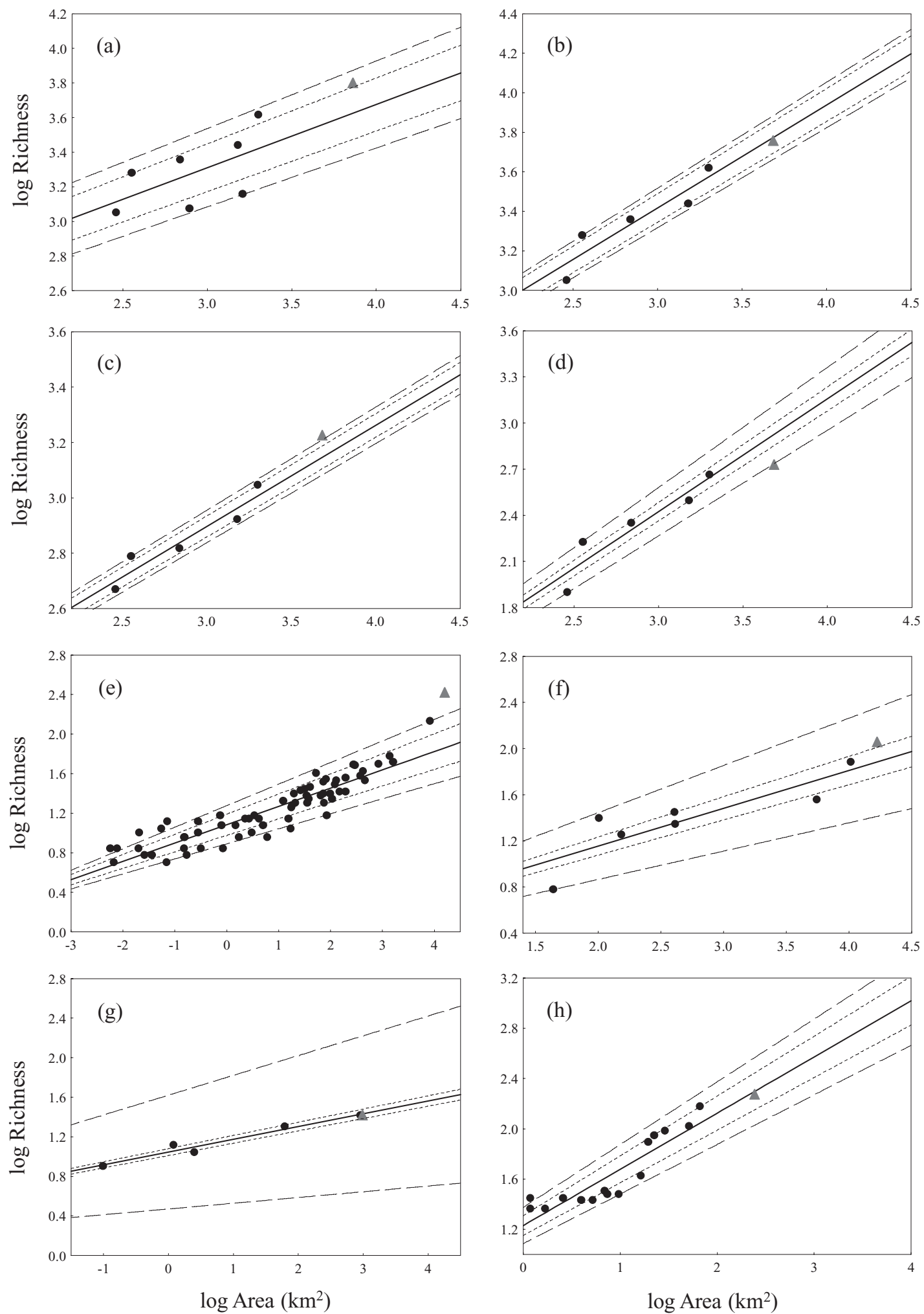

Figure 1 Relationship between species richness and area for several archipelago/taxon combinations. Individual islands are represented by black circles and the archipelagos by grey triangles. The island species-area relationship (ISAR) predicted by the regression function is shown as a continuous line in each case. The intervals defined by the maximum and median residuals criteria (see text) are represented by the dashed and the dotted lines, respectively: (a) Canary Islands - arthropods (all islands); (b) Canary Islands - arthropods (without Fuerteventura and Lanzarote); (c) Canary Islands - Coleoptera (without Fuerteventura and Lanzarote); (d) Canary Islands - Lepidoptera (without Fuerteventura and Lanzarote); (e) Aegean Islands - land snails; (f) Fiji - ants; (g) Chatman Islands - birds; (h) Cook Islands plants. See data sources and regression statistics in Appendix 1. 


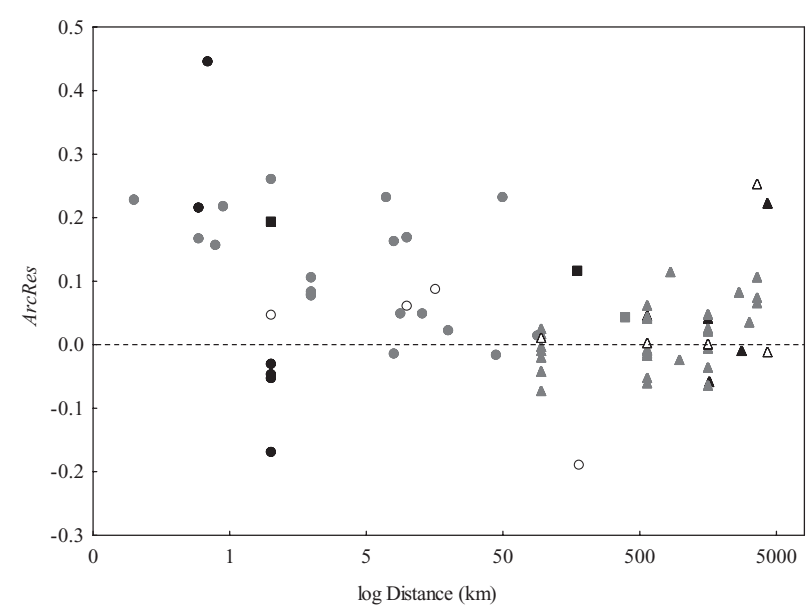

Figure 2 Distribution of the archipelagic residual (ArcRes) for the 72 significant archipelago/taxon combinations, according to the logarithm of the distance to the mainland (in km). ArcRes was calculated as the residual of the prediction provided by the island species-area relationship (ISAR) using the total area of the archipelago, standardized by the total richness observed in the archipelago. The symbol shade represents the type of taxon (black, vertebrates; grey, invertebrates; white, plants), and their shapes represent the type of archipelago (circles, continental; triangles, oceanic; squares, mixed archipelagos). The horizontal line serves only as a guide line to ArcRes $=0$.

Given that area is one of the best macroecological descriptors of island species richness (see, e.g., Rosenzweig, 1995; Whittaker \& Fernández-Palacios, 2007; Triantis et al., 2008a), the island group as a whole should also be expected to follow its endogenous species-area dynamics. We thus argue that if the archipelago is sufficiently isolated for all the islands to have an equivalent species pool, and the geological characteristics and evolutionary processes are coherent from island to island, it is unsurprising that the biota of the whole of the archipelago would follow the same relationship with area as the one operating within the constituent islands. In other words, the accumulation of new species with additional islands will show a consistent relationship with their area. It follows from our rationale that the departure of the archipelago from the ISAR will be related to some extent to the degree of nestedness of the island biotas (see also Wright et al., 1998).

The additional analyses carried out on several arthropod groups of the Canary Islands and the Azores show that the magnitude of the departure of the archipelago from the ISAR is related to nestedness. The more nested the biota of the archipelago, the lower the archipelagic residual, a trend that is especially evident when using the Temperature metric. The sensitivity to the choice of nestedness metric [Temperature metric of Atmar \& Patterson (1993) versus NODF metric of AlmeidaNeto et al. (2008)] might reflect the nature of the nestedness patterns. While traditional 'gap-counting' nestedness metrics such as Temperature are biased towards the loss of species among islands, NODF also accounts for the degree of coincidence of species presences in the poorer sites (see Almeida-Neto a)

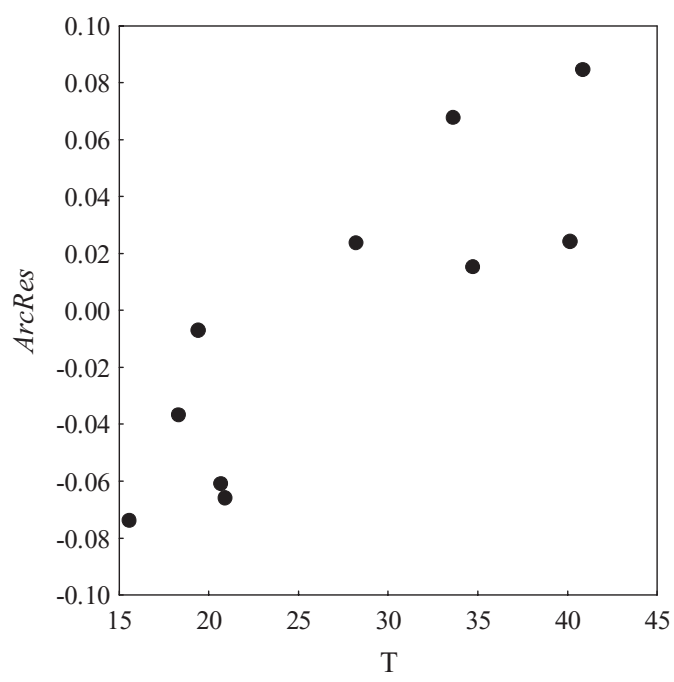

b)

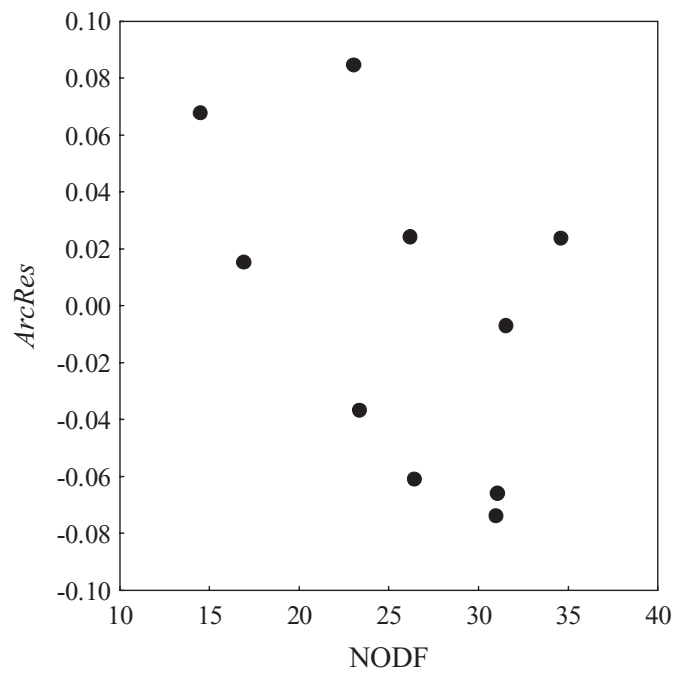

Figure 3 Relationship between the archipelagic residual (ArchRes) and two nestedness measures: (a) Temperature (T), the original measure proposed by Atmar \& Patterson (1993), and (b) the overlap and decreasing fill metric (NODF) proposed by Almeida-Neto et al. (2008). Note that the higher the NODF, the more nested the archipelago, which is the converse of the ordering of the T metric. Data correspond to several arthropod groups of the Azores and the Canary Islands (see Table 2).

et al., 2008; Ulrich et al., 2009). In other words, while Temperature values reflect how widespread species are distributed in progressively less rich islands, NODF also takes into account whether poor islands host rare species or not. These rare species are species present in just one or a few islands, so NODF would be expected to be more sensitive when the patterns of nestedness within the archipelago are driven by the numbers of single island endemics (SIEs). Within this framework, the less tight relationship between the archipelagic residual and NODF compared with its relationship with Temperature allows us to 
postulate that the number of SIEs per se does not necessarily have an effect on the departure of the archipelago from the ISAR. In fact, many cases with disproportionately high numbers of SIEs (and therefore highly non-nested biotas) fall into the confidence intervals we used in this work [e.g. Hawaiian land snails (Cowie, 1995) and lobeliads (Givnish et al., 2009)].

The residual variation of the archipelagic data point seems thus to reflect a particular aspect of nestedness: the absence of species present in the richer islands in progressively poorer islands (i.e. richness-ordered nestedness sensu Whittaker \& Fernández-Palacios, 2007). Departures from the ISAR are thus expected in systems that are either highly nested or not nested at all (Fig. 4), independently of the number of SIEs. In the case of highly nested systems, the richness of the archipelago will scarcely exceed that of the largest island and will be fairly insensitive to the number and area of smaller islands. Thus, the predicted number of species for the total area of the archipelago will be higher than the observed species richness (e.g. Lepidoptera from the Canary Islands; Fig. 1d). Conversely, in highly nonnested systems there is a high rate of accumulation of new species with the addition of each island. Hence, the observed archipelagic species richness (a cumulative total) should be higher than that predicted by the non-cumulative series provided by the ISAR (e.g. Coleoptera of the Canary Islands or land snails of the Aegean Islands; Fig. 1c,e). However, as discussed above, high overall numbers of SIE in the archipelago are not enough to cause significant departures from the ISAR (e.g. the highly species rich land snails and lobeliads of Hawaii mentioned above). Rather, departures will appear when the processes leading to the appearance of high numbers of SIE differ within the set of islands collated together for an analysis. Where an archipelago is composed of different groups of islands with

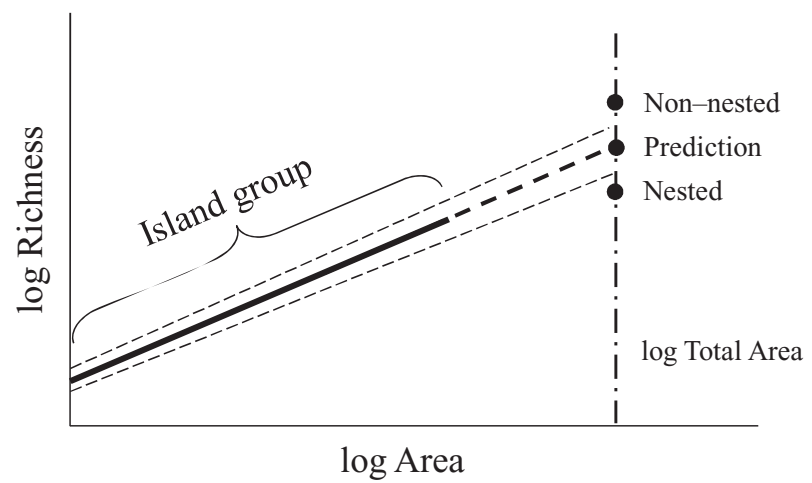

Figure 4 Hypothetical relationships between different degrees of nestedness and the departure of the archipelago point from the island species-area relationship (ISAR), in a log-log species-area plot. Here, nestedness is a by-product of the rate of accumulation of new species to the total list of the archipelago with the addition of new islands (i.e. richness-ordered nestedness sensu Whittaker \& Fernández-Palacios, 2007). Where a system tends towards perfect nestedness, the archipelago richness will be the same as that of the largest island (or only a little higher), while for completely unnested systems the archipelago richness is the sum of the richness of each constituent island. differing characteristics, the processes building up island biotas might vary amongst the constituent islands. This will happen in archipelagos where: (1) the proximity to the source(s) of colonizers allows inter-island variation in colonization rates and/or the arrival probability of particular species or lineages (thus different sets of widespread species will be found in different clusters of islands); (2) one or some of the islands show higher speciation rates (e.g. because they are significantly larger; see Losos \& Schluter, 2000); and also (3) some islands suffer anomalous pulses of extinction (e.g. island sterilization processes; see Whittaker \& Fernández-Palacios, 2007). All these cases will produce anomalous patterns of species accumulation with area, and the departure of the overall richness of the archipelago from the ISAR of its constituent islands.

This raises a more general point: almost all situations where the archipelagic point deviates significantly from the ISAR came from cases where both the slope of the ISAR and the degree of isolation were low, and the total species richness was higher than expected by the ISAR. Given that the ISAR slopes of these exceptional cases are low, it is not surprising that the total richness of the archipelago falls above the relationship observed for the islands, as seen for the Coleoptera of the Canary Islands or the land snails of the Aegean Islands (Fig. 1c,e, respectively). The reasons for such a non-nested pattern could be: (1) a particularly high speciation rate and/or particular patterns in clusters of islands (i.e. limitations to dispersal and availability of ecological space that allow a higher number of speciation events and thus the generation of large numbers of species over the whole archipelago); (2) a heterogeneous geological history among the individual islands, enough to differentiate sets of islands with particular dynamics (e.g. the Canary Islands; see Whittaker et al., 2008); or (3) multiple sources for the arrival of new species (which is the case for the Aegean Islands). Conversely, highly nested systems might arise from several circumstances, including: (4) a low rate of colonization from the continent, which will result in a small number of lineages inhabiting the archipelago, and thus lower compositional replacement; and (5) high rates of dispersal between islands, which will also result in low compositional replacement from island to island. Canarian Lepidoptera provided the only example in which the overall richness of the archipelagic point falls significantly below the ISAR according to our maximum residual criterion, indicating a low degree of dissimilarity for this group (see Fig. 1d). Butterflies and moths are in general very good dispersers (e.g. Borges \& Hortal, 2009), which results in low compositional differences between island faunas (our reason 5). Hence, the total species richness of the archipelago does not increase significantly with the addition of new islands.

Our analytical approach presents several limitations that reflect the exploratory nature of our study. For example, many of the cases we studied pertain to just five island groups (Aegean Islands, Azores, Canary Islands, Cape Verde and Hawaii) for which relatively comprehensive data are available. As a consequence, although the results from these archipelagos reassure us that our conclusions are reliable in broad qualitative terms, we cannot be sure that these results will also turn 
out to be reliable in quantitative terms. Given the relationship between the degree of departure of the ISAR and nestedness found here, we recommend that further research on this topic should rely on the development of null models of the relationship between area and species assembly in a presence/absence matrix. The assumptions and development of these models are currently under debate, and several null hypotheses for random assembly have been proposed so far (see, e.g., Wright et al., 1998; Rodríguez-Gironés \& Santamaría, 2006; AlmeidaNeto et al., 2007, 2008; Ulrich et al., 2009). In fact, these null hypotheses correspond to different aspects of nestedness: richness ordered or area ordered (see also Whittaker \& FernándezPalacios, 2007; Ulrich etal., 2009). We anticipate that departures from the null expectations of these models would depend on the disparity in the presence of widespread species among islands, rather than on the number of rare species (e.g. SIE; see above). Therefore, we hypothesize that these departures would provide insight into the processes determining the assembly of island biotas within the archipelago, such as varying geological histories, island isolation or habitat diversity (see, e.g., Roughgarden, 1989; Lomolino \& Davis, 1997; Hortal et al., 2009), but they will be relatively independent of differences in the evolutionary processes among islands.

To summarize, we have shown that archipelagos usually follow the same species-area relationship as their constituent islands. A straightforward implication of our results is that archipelagos can, in most cases, be considered as distinct entities. Hence, researchers would be justified in lumping species lists from their constituent islands when conducting biogeographical and/or macroecological studies. It is also important to note that most of the archipelagos studied are in fact 'SLOSS neutral' (sensu Rosenzweig, 2004), and thus that at this large scale whether conservation efforts are devoted to a single large island or to several small ones may be of limited relevance (see also Rosenzweig, 2004). Importantly, the degree of departure from the ISAR (i.e. the archipelagic residual) is related to a particular aspect of nestedness, the loss of species present on the richest islands from the poorer ones, and can therefore be used as a crude index of richness-ordered nestedness when detailed island checklists are lacking. Given that area is just one of a number of factors determining the species richness on islands, within this framework the departure of some archipelagos from their ISAR would be caused by other factors affecting the assembly of island faunas, and therefore nestedness patterns (see Wright et al., 1998). Further studies are required to understand the complexities of the influence of these factors on the degree of departure of the archipelagic point from the ISAR and the exact nature of the relationship between such departure and nestedness, and also to establish the pattern of departure of archipelagic data points from their constituent ISARs for other types of insular system, including anthropogenic habitat islands in fragmented landscapes.

\section{ACKNOWLEDGEMENTS}

We thank three anonymous referees for their critical comments. A.M.C.S. was supported by a Portuguese FCT grant (SFRH/BD/
21496/2005), K.A.T. by a Marie Curie Intra-European Fellowship Program (project 'SPAR', 041095) and the Academic Visitors Program of the NERC Centre for Population Biology, P.A.V.B. by CITA-A, and J.H. by the UK Natural Environment Research Council.

\section{REFERENCES}

Adler, G.H. (1992) Endemism in birds of tropical Pacific islands. Evolutionary Ecology, 6, 296-306.

Adler, G.H. (1994) Avifaunal diversity and endemism on tropical Indian Ocean islands. Journal of Biogeography, 21, 8595.

Adler, G.H. \& Dudley, R. (1994) Butterfly biogeography and endemism on tropical Pacific islands. Biological Journal of the Linnean Society, 51, 151-162.

Adler, G.H., Austin, C.C. \& Dudley, R. (1995) Dispersal and speciation of skinks among archipelagos in the tropical Pacific Ocean. Evolutionary Ecology, 9, 529-541.

Almeida-Neto, M., Guimarães, P.R., Jr \& Lewinsohn, T.M. (2007) On nestedness analyses: rethinking matrix temperature and anti-nestedness. Oikos, 116, 716-722.

Almeida-Neto, M., Guimarães, P., Guimarães, P.R., Jr, Loyola, R.D. \& Ulrich, W. (2008) A consistent metric for nestedness analysis in ecological systems: reconciling concept and measurement. Oikos, 117, 1227-1239.

Arechavaleta, M., Zurita, N., Marrero, M.C. \& Martin, J.L. (2005) Lista preliminar de especies silvestres de Cabo Verde (hongos, plantas y animales terrestres). Consejería de Medio Ambiente y Ordenación Territorial, Gobierno de Canarias, La Laguna, Tenerife.

Arrhenius, O. (1921) Species and area. Journal of Ecology, 9, 95-99.

Atmar, W. \& Patterson, B.D. (1993) The measure of order and disorder in the distribution of species in fragmented habitat. Oecologia, 96, 373-382.

Azeria, E.T. (2004) Terrestrial bird community patterns on the coralline islands of the Dahlak Archipelago, Red Sea, Eritrea. Global Ecology and Biogeography, 13, 177-187.

Beck, J. \& Kitching, I.J. (2004-2008) The Sphingidae of Southeast Asia (incl. New Guinea, Bismarck and Solomon Islands), version 1.5. Available at: http://www.sphin-sea.unibas.ch/ (accessed 15 June 2008).

Bennett, D.J. (2008) The ophionine wasps of Hawaii (Hymenoptera: Ichneumonidae). Journal of Hymenoptera Research, 17, 1-43.

Biber, E. (2002) Patterns of endemic extinctions among island bird species. Ecography, 25, 661-676.

Blackburn, T.M., Cassey, P., Duncan, R.P., Evans, K.L. \& Gaston, K.J. (2004) Avian extinctions and mammalian introductions on oceanic islands. Science, 305, 1955-1958.

Borges, P.A.V. \& Hortal, J. (2009) Time, area and isolation: factors driving the diversification of Azorean arthropods. Journal of Biogeography, 36, 178-191.

Borges, P.A.V., Cunha, R., Gabriel, R., Martins, A.F., Silva, L. \& Vieira, V. (2005) A list of the terrestrial fauna (Gastropoda and 
Arthropoda) and flora from the Azores. Direcção Regional de Ambiente e do Mar dos Açores, Horta, Faial.

Carvajal, A. \& Adler, G.H. (2005) Biogeography of mammals on tropical Pacific islands. Journal of Biogeography, 32, 15611569.

Conroy, C.J., Demboski, J.R. \& Cook, J.A. (1999) Mammalian biogeography of the Alexander Archipelago of Alaska: a north temperate nested fauna. Journal of Biogeography, 26, 343-352.

Cowie, R.H. (1995) Variation in species diversity and shell shape in Hawaiian land snails: in situ speciation and ecological relationships. Evolution, 49, 1191-1202.

Dapporto, L. \& Cini, A. (2007) Faunal patterns in Tuscan archipelago butterflies: the dominant influence is recent geography not paleogeography. European Journal of Entomology, 104, 497-503.

Dapporto, L. \& Dennis, R.L.H. (2008) Species richness, rarity and endemicity on Italian offshore islands: complementary signals from island-focused and species-focused analyses. Journal of Biogeography, 35, 664-674.

Dengler, J. (2009) Which function describes the species-area relationship best? A review and empirical evaluation. Journal of Biogeography, 36, 728-744.

Fattorini, S. (2002) Biogeography of the tenebrionid beetles (Coleoptera, Tenebrionidae) on the Aegean Islands (Greece). Journal of Biogeography, 29, 49-67.

Gaston, K.J. \& Blackburn, T.M. (2000) Pattern and process in macroecology. Blackwell Science, Oxford.

Givnish, T.J., Millam, K.C., Mast, A.R., Paterson, T.B., Theim, T.J., Hipp, A.L., Henss, J.M., Smith, J.F., Wood, K.R. \& Sytsma, K.J. (2009) Origin, adaptive radiation and diversification of the Hawaiian lobeliads (Asterales: Campanulaceae). Proceedings of the Royal Society B: Biological Sciences, 276, 407-416.

Gray, J.S., Ugland, K.I. \& Lambshead, J. (2004) On species accumulation and species-area curves. Global Ecology and Biogeography, 13, 567-568.

Guimarães, J.P.R. \& Guimarães, P. (2006) Improving the analyses of nestedness for large sets of matrices. Environmental Modelling and Software, 21, 1512-1513.

Hamilton, A.M., Hartman, J.H. \& Austin, C.C. (2009) Island area and species diversity in the southwest Pacific Ocean: is the lizard fauna of Vanuatu depauperate? Ecography, 32, 247-258.

He, F.L., Gaston, K.J., Connor, E.F. \& Srivastava, D.S. (2005) The local-regional relationship: immigration, extinction, and scale. Ecology, 86, 360-365.

Holyoak, G.A., Turk, S.M. \& Cameron, R.A.D. (2005) Land molluscs on the Isles of Scilly: species richness and composition related to area. Journal of Conchology, 38, 549-560.

Hortal, J., Triantis, K.A., Meiri, S., Thébault, E. \& Sfenthourakis, S. (2009) Island species richness increases with habitat diversity. The American Naturalist, 173, E205-E217.

Izquierdo, I., Martín, J.L., Zurita, N. \& Arechavaleta, M. (2004) Lista de especies silvestres de Canarias (hongos, plantas y animales terrestres), 2nd edn. Consejería de Política Territorial y Medio Ambiente del Gobierno de Canarias, La Laguna, Tenerife.
Kohn, D.D. \& Walsh, D.M. (1994) Plant species richness - the effect of island size and habitat diversity. Journal of Ecology, 82, 367-377.

Kotze, D.J., Niemelä, J. \& Nieminen, M. (2000) Colonization success of carabid beetles on Baltic islands. Journal of Biogeography, 27, 807-819.

Kryštufek, B. \& Kletečki, E. (2007) Biogeography of small terrestrial vertebrates on the Adriatic landbridge islands. Folia Zoologica, 56, 225-234.

Lawton, J.H. (1996) Patterns in ecology. Oikos, 75, 145-147.

Lawton, J.H. (1999) Are there general laws in ecology? Oikos, 84, 177-192.

Lawton, J.H. (2000) Community ecology in a changing world. Ecology Institute, Oldendorf/Luhe, Germany.

Lomolino, M.V. \& Davis, R. (1997) Biogeographic scale and biodiversity of mountain forest mammals of western North America. Global Ecology and Biogeography Letters, 6, 57-76.

Losos, J.B. \& Schluter, D. (2000) Analysis of an evolutionary species-area relationship. Nature, 408, 847-850.

MacArthur, R.H. \& Wilson, E.O. (1963) An equilibrium theory of insular zoogeography. Evolution, 17, 373-387.

MacArthur, R.H. \& Wilson, E.O. (1967) The theory of island biogeography. Princeton University Press, Princeton, NJ.

McCormack, G. (2007) Cook Islands biodiversity database. Cook Islands Natural Heritage Trust, Rarotonga. Available at: http:// cookislands.bishopmuseum.org (accessed 17 November 2007)

Millien-Parra, V. \& Jaeger, J.-J. (1999) Island biogeography of the Japanese terrestrial mammal assemblages: an example of a relict fauna. Journal of Biogeography, 26, 959-972.

Mylonas, M.A. (1982) The zoogeography and ecology of the terrestrial molluscs of Cyclades [in Greek]. $\mathrm{PhD}$ Thesis, University of Athens, Athens, Greece.

Niemelä, J. (1988) Habitat occupancy of carabid beetles on small islands and the adjacent Aland mainland, SW Finland. Annales Zoologici Fennici, 25, 121-131.

Niemelä, J., Haila, Y., Ranta, E., Tiainen, J., Vepsäläinen, K. \& Ås, S. (1987) Distribution of carabid beetles in four boreal archipelagoes. Annales Zoologici Fennici, 24, 89-100.

Nishida, G.M. (2002) Hawaiian terrestrial arthropod checklist. Available at: http://www2.bishopmuseum.org/HBS/checklist/ query.asp?grp (accessed 22 February 2007).

Pandža, M. \& Stančić, Z. (2004) Second contribution to the flora of the Kornati islands (Croatia). Natura Croatica, 13, 4761.

Pandža, M., Franjić, J. \& Škvorc, Z. (2002) The flora of some uninhabited Šibenik archipelago islands (Dalmatia, Croatia). Natura Croatica, 11, 367-385.

Panitsa, M. \& Tzanoudakis, D. (1998) Contribution to the study of the Greek flora: flora and vegetation of the E Aegean islands Agathonisi and Pharmakonisi. Wildenowia, 28, 95-116.

Ricklefs, R.E. (2007) History and diversity: explorations at the intersection of ecology and evolution. The American Naturalist, 170, S56-S70.

Ricklefs, R.E. (2008) Disintegration of the ecological community. The American Naturalist, 172, 741-750. 
Rodríguez-Gironés, M.A. \& Santamaría, L. (2006) A new algorithm to calculate the nestedness temperature of presenceabsence matrices. Journal of Biogeography, 33, 924-935.

Rosenzweig, M.L. (1995) Species diversity in space and time. Cambridge University Press, Cambridge, UK.

Rosenzweig, M.L. (2003) Reconciliation ecology and the future of species diversity. Oryx, 37, 194-205.

Rosenzweig, M.L. (2004) Applying species-area relationships to the conservation of diversity. Frontiers of biogeography: new directions in the geography of nature (ed. by M.V. Lomolino and L.R. Heaney), pp. 325-343. Sinauer Associates, Sunderland, MA.

Roughgarden, J. (1989) The structure and assembly of communities. Perspectives in ecological theory (ed. by J. Roughgarden, R.M. May and S.A. Levin), pp. 203-226. Princeton University Press, Princeton.

Schatz, H. (1998) Oribatid mites of the Galápagos Islands faunistics, ecology and speciation. Experimental and Applied Acarology, 22, 373-409.

Scheiner, S.M. (2003) Six types of species-area curves. Global Ecology and Biogeography, 12, 441-447.

Schoener, T.W. (1976) The species-area relation within archipelagos: models and evidence from island birds. Proceedings of the XVI International Ornithological Congress, 6, 629-642.

Scott, J.A. (1972) Biogeography of Antillean butterflies. Biotropica, 4, 32-45.

Sfenthourakis, S. (1996) A biogeographical analysis of terrestrial isopods (Isopoda, Oniscidea) from the central Aegean islands (Greece). Journal of Biogeography, 23, 687-698.

Sfenthourakis, S., Giokas, S. \& Tzanatos, E. (2004) From sampling stations to archipelagos: investigating aspects of the assemblage of insular biota. Global Ecology and Biogeography, 13, 23-35.

Sheremet'ev, I.S. (2004) Stability of isolated populations of terrestrial mammals inhabiting the islands of the Peter the Great Bay, Sea of Japan. Russian Journal of Ecology, 35, 171-175.

Simberloff, D. (2004) Community ecology: is it time to move on? The American Naturalist, 163, 787-799.

Srivastava, D.S. (1999) Using local-regional richness plots to test for species saturation: pitfalls and potentials. Journal of Animal Ecology, 68, 1-16.

StatSoft (2003) STATISTICA (data analysis software system), version 6.1. StatSoft Inc., Tulsa, OK.

Tomiyama, K. \& Kurozumi, T. (1992) Terrestrial mollusks and conservation of their environment in the Ogasawara Islands [in Japanese with English summary]. Regional Views, 5, 39-81.

Triantis, K.A., Mylonas, M., Weiser, M.D., Lika, K. \& Vardinoyannis, K. (2005) Species richness, environmental heterogeneity and area: a case study based on land snails in Skyros archipelago (Aegean Sea, Greece). Journal of Biogeography, 32, 1727-1735.

Triantis, K.A., Mylonas, M. \& Whittaker, R.J. (2008a) Evolutionary species-area curves as revealed by single-island endemics: insights for the inter-provincial species-area relationship. Ecography, 31, 401-407.

Triantis, K.A., Vardinoyannis, K. \& Mylonas, M. (2008b) Biogeography, land snails and incomplete data sets: the case of three island groups in the Aegean Sea. Journal of Natural History, 42, 467-490.

Trichas, A., Lagkis, A., Triantis, K.A., Poulakakis, N. \& Chatzaki, M. (2008) Biogeographic patterns of tenebrionid beetles (Coleoptera, Tenebrionidae) on four island groups in the south Aegean Sea. Journal of Natural History, 42, 491-511.

Ulrich, W., Almeida-Neto, M. \& Gotelli, N.J. (2009) A consumer's guide to nestedness analysis. Oikos, 118, 3-17.

Wallace, A.R. (1902) Island life, 3rd edn. Macmillan, London.

Ward, D.F. \& Wetterer, J.K. (2006) Checklist of the ants of Fiji (Hymenoptera: Formicidae). Fiji Arthropods III (ed. by N.L. Evenhuis and D.J. Bickel), Bishop Museum Occasional Papers, No. 85, pp. 23-47.

Welter-Schultes, F.W. \& Williams, M.R. (1999) History, island area and habitat availability determine land snail species richness of Aegean islands. Journal of Biogeography, 26, 239-249.

Whittaker, R.J. \& Fernández-Palacios, J.M. (2007) Island biogeography: ecology, evolution, and conservation, 2nd edn. Oxford University Press, Oxford.

Whittaker, R.J., Triantis, K.A. \& Ladle, R.J. (2008) A general dynamic theory of oceanic island biogeography. Journal of Biogeography, 35, 977-994.

Williams, G.R. (1981) Aspects of avian island biogeography in New Zealand. Journal of Biogeography, 8, 439-456.

Wilson, E.O. (1961) The nature of the taxon cycle in the Melanesian ant fauna. The American Naturalist, 95, 169-193.

Wilson, E.O. \& Hunt, G.L. (1967) Ant fauna of Futuna and Wallis Islands, stepping stones to Polynesia. Pacific Insects, 9, 563-584.

Woinarski, J.C.Z., Reichel, H. \& Andersen, A.N. (1998) The distribution of ants on the Wessel and English Company Islands, in the seasonal tropics of Australia's Northern Territory. Australian Journal of Zoology, 46, 557-579.

Wright, D.H. (1983) Species-energy theory - an extension of species-area theory. Oikos, 41, 496-506.

Wright, D.H., Patterson, B.D., Mikkelson, G.M., Cutler, A. \& Atmar, W. (1998) A comparative analysis of nested subset patterns of species composition. Oecologia, 113, 1-20.

Zalewski, M. \& Ulrich, W. (2006) Dispersal as a key element of community structure: the case of ground beetles on lake islands. Diversity and Distributions, 12, 767-775. 


\section{BIOSKETCHES}

Ana M. C. Santos is a PhD student at Imperial College London. She studies island biogeography, comparing the host-parasitoid interactions between islands and mainland. She is also interested in the applicability of species-area relationships on different scales and the potential biases in databases.

Robert J. Whittaker, Kostas A. Triantis, Paulo A. V. Borges and Joaquín Hortal are interested in island biogeography, among other topics. Owen R. Jones and Donald L. J. Quicke work on the macroevolution of parasitoids.

Author contributions: A.M.C.S., R.J.W., K.A.T. and J.H. conceived the ideas; A.M.C.S., K.A.T. and P.A.V.B. gathered the data; A.M.C.S. and J.H. analysed the data; and A.M.C.S., R.J.W., K.A.T. and J.H. wrote the paper with P.A.V.B., O.R.J. and D.L.J.Q. All authors discussed the results and commented on the manuscript.

Editor: Brian McGill

Appendix 1 Characteristics of the archipelago/taxon combinations studied, and results of the species-area regressions and the degree of departure of the archipelagic point from its island species-area relationship (ISAR).

\begin{tabular}{|c|c|c|c|c|c|c|c|c|c|c|c|c|c|}
\hline & Archipelago & $I$ & $n$ & $A$ & G & Taxon & $S_{\mathrm{obs}}$ & $S A_{\text {pred }}$ & Slope & Inter. & $R^{2}$ & Interval & Ref. \\
\hline \multirow{32}{*}{ 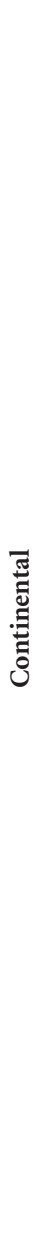 } & Adriatic Islands & 1 & 13 & 2586 & V & Amphibians & 7 & 9.8 & 0.50 & -0.70 & $0.52^{\star \star}$ & Max, Med & 1 \\
\hline & Adriatic Islands & 1 & 14 & 2638 & $\mathrm{~V}$ & Mammals & 13 & 14.1 & 0.29 & 0.15 & $0.69^{\star * *}$ & Max, Med & 1 \\
\hline & Adriatic Islands & 1 & 14 & 2638 & $\mathrm{~V}$ & Reptiles & 28 & 33.4 & 0.36 & 0.29 & $0.79^{* * *}$ & Max, Med & 1 \\
\hline & Adriatic Islands & 1 & 14 & 2638 & $\mathrm{~V}$ & Vertebrates & 48 & 57.8 & 0.36 & 0.52 & $0.78^{\star * *}$ & Max, Med & 1 \\
\hline & Aegean Islands & 2 & 44 & 3562 & I & Isopods & 69 & 49.6 & 0.20 & 0.97 & $0.91^{\star * *}$ & Max & 2 \\
\hline & Aegean Islands & 2 & 20 & 3371 & I & Isopods & 59 & 42.3 & 0.21 & 0.88 & $0.59^{\star * *}$ & - & 3 \\
\hline & Aegean Islands & 7 & 65 & 15,853 & I & Land snails & 264 & 72.5 & 0.19 & 1.08 & $0.83^{\star * *}$ & - & 4 \\
\hline & Aegean Islands & 7 & 64 & 7593 & I & Land snails ${ }^{1}$ & 196 & 59.4 & 0.18 & 1.08 & 0.83 & - & 4 \\
\hline & Aegean Islands & 10 & 9 & 18 & $\mathrm{P}$ & Plants & 402 & 279.8 & 0.35 & 2.00 & $0.78^{\star \star}$ & Max, Med & 5 \\
\hline & Aegean Islands & 0.1 & 32 & 20,313 & I & Tenebrionids & 126 & 41.9 & 0.28 & 0.41 & $0.41^{\star * \star}$ & $\operatorname{Max}$ & 6 \\
\hline & Aegean Islands & 8 & 26 & 369 & I & Tenebrionids & 59 & 30.5 & 0.28 & 0.78 & $0.75^{\star * \star}$ & Max & 7 \\
\hline & Åland Archipelago & 0.25 & 5 & 1 & I & Carabids & 33 & 23.0 & 0.21 & 1.40 & 0.47 & - & 8 \\
\hline & Alexander Archipelago & 0.35 & 24 & 32,707 & $\mathrm{~V}$ & Mammals & 23 & 5.7 & 0.19 & -0.10 & $0.95^{\star * *}$ & Max & 9 \\
\hline & Baltic Islands & 0.3 & 24 & 78 & I & Carabids & 61 & 30.8 & 0.11 & 1.28 & $0.47^{\star * *}$ & - & 10 \\
\hline & Cyclades & 13 & 24 & 2437 & I & Land snails & 82 & 62.1 & 0.27 & 0.89 & $0.64^{\star * *}$ & Max & 11 \\
\hline & Italian Islands & 0.45 & 31 & 1234 & I & Lepidoptera & 86 & 32.6 & 0.13 & 1.11 & $0.21^{\star}$ & $\operatorname{Max}$ & 12 \\
\hline & Kalymnos Islands & 8 & 12 & 132 & I & Land snails & 47 & 49.9 & 0.20 & 1.28 & $0.81^{\star \star \star}$ & Max, Med & 13 \\
\hline & Kornati Archipelago & 16 & 5 & 34 & $\mathrm{P}$ & Plants & 634 & 363.3 & 0.28 & 2.13 & $0.92^{\star}$ & - & 14 \\
\hline & Lake Mamri Islands & 0.4 & 15 & 51 & I & Carabids & 71 & 36.4 & 0.14 & 1.60 & $0.66^{* * *}$ & - & 15 \\
\hline & Peter the Great Bay Isl. & 0.3 & 11 & 161 & $\mathrm{~V}$ & Mammals & 19 & 10.1 & 0.31 & 0.31 & $0.39^{\star}$ & Max, Med & 16 \\
\hline & Pihlajavesi Archipelago & 2 & 13 & 1 & I & Carabids & 23 & 16.5 & 0.33 & 1.24 & $0.37^{\star}$ & Max, Med & 17 \\
\hline & Sardinian-Corsican Isl. & 50 & 11 & 326 & I & Lepidoptera & 65 & 24.7 & 0.15 & 1.01 & $0.49^{*}$ & - & 12 \\
\hline & Scilly Isles & 45 & 7 & 14 & I & Land snails & 51 & 54.6 & 0.36 & 1.34 & $0.85^{\star *}$ & Max, Med & 18 \\
\hline & Shetland Islands & 180 & 42 & 3 & $\mathrm{P}$ & Plants & 81 & 186.1 & 0.48 & 2.03 & $0.73^{\star * *}$ & $\operatorname{Max}$ & 19 \\
\hline & Šibenik Archipelago & 1 & 10 & 10 & $\mathrm{P}$ & Plants & 278 & 214.8 & 0.18 & 2.15 & $0.94^{\star * *}$ & - & 20 \\
\hline & Sicilian Islands & 22 & 10 & 525 & I & Lepidoptera & 30 & 20.1 & 0.09 & 1.07 & 0.17 & $\operatorname{Max}$ & 12 \\
\hline & Skyros Archipelago & 90 & 12 & 221 & I & Land snails & 42 & 40 & 0.18 & 1.19 & $0.88^{\star * \star}$ & Max, Med & 21 \\
\hline & Stockolm Archipelago & 10 & 12 & 4 & I & Carabids & 28 & 16 & 0.30 & 1.03 & $0.52^{\star \star}$ & $\operatorname{Max}$ & 17 \\
\hline & Tuscan Archipelago & 9 & 7 & 290 & I & Lepidoptera & 67 & 54.6 & 0.35 & 0.88 & $0.73^{\star}$ & Max & 22 \\
\hline & Tvarminne Archipelago & 1 & 16 & $<1$ & I & Carabids & 19 & 8.8 & 0.28 & 1.08 & $0.47^{\star \star}$ & $\operatorname{Max}$ & 17 \\
\hline & Vargskar Archipelago & 20 & 13 & 2 & I & Carabids & 42 & 38.6 & 0.33 & 1.50 & $0.74^{\star * *}$ & Max, Med & 17 \\
\hline & Wessel Islands & 2 & 37 & 513 & I & Ants & 74 & 53.2 & 0.28 & 0.96 & $0.68^{\star * *}$ & Max, Med & 23 \\
\hline \multirow{3}{*}{ 总 } & Dahlak Archipelago & 1 & 26 & 75 & $\mathrm{~V}$ & Birds & 38 & 18.8 & 0.31 & 0.70 & $0.52^{\star * \star}$ & Max, Med & 24 \\
\hline & Japan & 175 & 10 & 367,697 & $\mathrm{~V}$ & Mammals & 55 & 34.6 & 0.23 & 0.28 & $0.77^{* * *}$ & - & 25 \\
\hline & Mollucas & 400 & 15 & 58,534 & I & Sphingidae & 83 & 68.7 & 0.55 & -0.81 & $0.42^{\star *}$ & Max, Med & 26 \\
\hline
\end{tabular}


Appendix 1 Continued

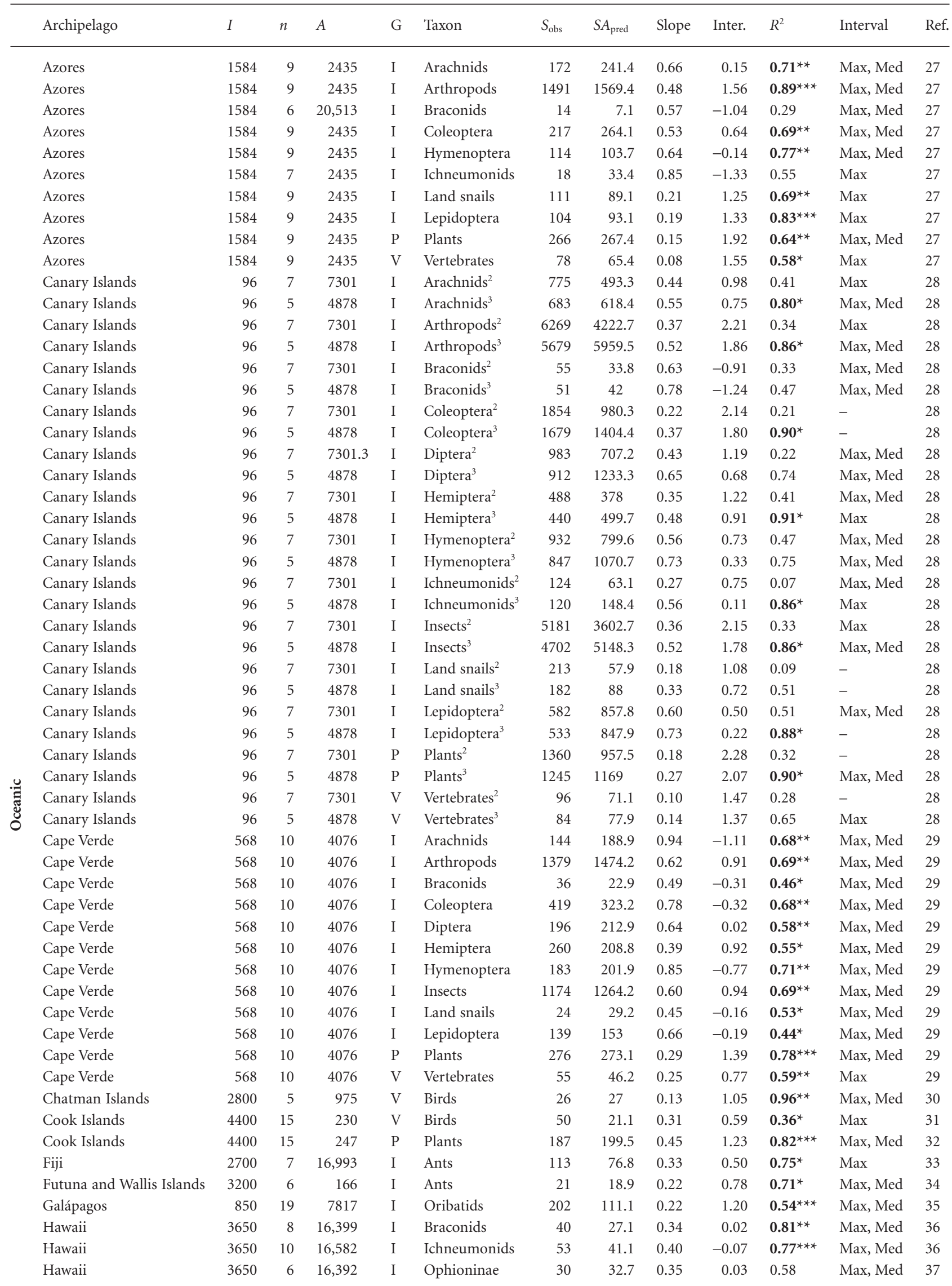


A. M. C. Santos et al.

Appendix 1 Continued

\begin{tabular}{|c|c|c|c|c|c|c|c|c|c|c|c|c|}
\hline Archipelago & $I$ & $n$ & $A$ & G & Taxon & $S_{\text {obs }}$ & $S A_{\text {pred }}$ & Slope & Inter. & $R^{2}$ & Interval & Ref. \\
\hline Hawaii & 3650 & 10 & 16,397 & I & Land snails & 752 & 462.2 & 0.58 & 0.21 & $0.93^{* * *}$ & Max, Med & 38 \\
\hline Hawaii & 3650 & 8 & 16,885 & $\mathrm{P}$ & Lobeliads & 76 & 62.9 & 0.73 & -1.31 & $0.67^{\star}$ & Max, Med & 39 \\
\hline New Zealand & 1641 & 23 & 267,039 & V & Birds & 60 & 76.3 & 0.19 & 0.87 & $0.74^{\star * *}$ & Max, Med & 30 \\
\hline Ogasawara Islands & 1000 & 16 & 71 & I & Land snails & 92 & 102.8 & 0.64 & 0.82 & $0.79^{* * *}$ & Max, Med & 40 \\
\hline Solomon Islands & 1500 & 12 & 23,955 & I & Sphingidae & 38 & 21.6 & 0.38 & -0.32 & 0.22 & Max, Med & 26 \\
\hline
\end{tabular}

$I$ is the smallest distance to the closest source of immigrants (in $\mathrm{km}$ ), $n$ is the number of islands considered, and $A$ is the sum of their areas (in $\mathrm{km}^{2}$ ). $\mathrm{G}$ is the kind of taxon studied (V, vertebrates; I, invertebrates; P, plants). The studied data usually refer to all the islands present in the respective reference (Ref.), except when indicated ( ${ }^{1}$ all Aegean islands except Crete; ${ }^{2}$ all Canary Islands; ${ }^{3}$ all Canary Islands except Fuerteventura and Lanzarote). $S_{\text {obs }}$ is the total species richness, and $S A_{\text {pred }}$ is the richness for the whole archipelago predicted by the ISAR, according to the relationship defined by the slope and intercept (Inter.) of the regression equation given by the log-log form of the power model. $R^{2}$ is the variability explained by the equation (significant ISARs are in bold; $\left.{ }^{*} P<0.05 ;{ }^{* *} P<0.01 ;{ }^{* *} P<0.001\right)$. Finally, Interval describes whether the archipelago is congruent with its ISAR or not, according to two criteria, the maximum (Max) and median (Med) residual (see text for further details).

The source references (Ref.) for all datasets are as follows: (1) Kryštufek \& Kletečki (2007); (2) Sfenthourakis (1996); (3) Sfenthourakis et al. (2004); (4) Welter-Schultes \& Williams (1999); (5) Panitsa \& Tzanoudakis (1998); (6) Fattorini (2002); (7) Trichas et al. (2008); (8) Niemelä (1988); (9) Conroy et al. (1999); (10) Kotze et al. (2000); (11) Mylonas (1982); (12) Dapporto \& Dennis (2008); (13) Triantis et al. (2008b); (14) Pandža \& Stančić (2004); (15) Zalewski \& Ulrich (2006); (16) Sheremet'ev (2004); (17) Niemelä et al. (1987); (18) Holyoak et al. (2005); (19) Kohn \& Walsh (1994); (20) Pandža et al. (2002); (21) Triantis et al. (2005); (22) Dapporto \& Cini (2007); (23) Woinarski et al. (1998); (24) Azeria (2004); (25) Millien-Parra \& Jaeger (1999); (26) Beck \& Kitching (2004-2008); (27) Borges et al. (2005); (28) Izquierdo et al. (2004); (29) Arechavaleta et al. (2005); (30) Williams (1981); (31) Blackburn et al. (2004); (32) McCormack (2007); (33) Ward \& Wetterer (2006); (34) Wilson \& Hunt (1967); (35) Schatz (1998); (36) Nishida (2002); (37) Bennett (2008); (38) Cowie (1995); (39) Givnish et al. (2009); (40) Tomiyama \& Kurozumi (1992). 